\title{
A new airborne laser-induced fluorescence instrument for in situ detection of formaldehyde throughout the troposphere and lower stratosphere
}

\author{
M. Cazorla ${ }^{1, *}$, G. M. Wolfe ${ }^{1,2}$, S. A. Bailey ${ }^{1}$, A. K. Swanson ${ }^{1,3}$, H. L. Arkinson ${ }^{4}$, and T. F. Hanisco ${ }^{1}$ \\ ${ }^{1}$ Atmospheric Chemistry and Dynamics Lab, NASA Goddard Space Flight Center, Greenbelt, MD, USA \\ ${ }^{2}$ Joint Center for Earth Systems Technology, University of Maryland Baltimore County, Baltimore, MD, USA \\ ${ }^{3}$ Goddard Earth Sciences Technology and Research, University of Maryland Baltimore County, Baltimore, MD, USA \\ ${ }^{4}$ Department of Atmospheric and Oceanic Science, University of Maryland, College Park, MD, USA \\ *now at: Universidad San Francisco de Quito, Instituto de Investigaciones Atmosféricas, Colegio de Ciencias e Ingeniería, \\ Diego de Robles y Vía Interoceánica, Quito, Ecuador
}

Correspondence to: T. F. Hanisco (thomas.hanisco@nasa.gov)

Received: 21 July 2014 - Published in Atmos. Meas. Tech. Discuss.: 19 August 2014

Revised: 13 November 2014 - Accepted: 9 December 2014 - Published: 3 February 2015

\begin{abstract}
The NASA In Situ Airborne Formaldehyde (ISAF) instrument is a high-performance laser-based detector for gas-phase formaldehyde (HCHO). ISAF uses rotational-state specific laser excitation at $353 \mathrm{~nm}$ for laserinduced fluorescence (LIF) detection of HCHO. A number of features make ISAF ideal for airborne deployment, including (1) a compact, low-maintenance fiber laser, (2) a single-pass design for stable signal response, (3) a straightforward inlet design, and (4) a stand-alone data acquisition system. A full description of the instrument design is given, along with detailed performance characteristics. The accuracy of reported mixing ratios is $\pm 10 \%$ based on calibration against IR and UV absorption of a primary HCHO standard. Precision at $1 \mathrm{~Hz}$ is typically better than $20 \%$ above $100 \mathrm{pptv}$, with uncertainty in the signal background contributing most to variability at low mixing ratios. The $1 \mathrm{~Hz}$ detection limit for a signal / noise ratio of 2 is $36 \mathrm{pptv}$ for $10 \mathrm{~mW}$ of laser power, and the $e$ fold time response at typical sample flow rates is $0.19 \mathrm{~s}$. ISAF has already flown on several field missions and platforms with excellent results.
\end{abstract}

\section{Introduction}

Formaldehyde (HCHO) is a ubiquitous constituent of the Earth's atmosphere. It is primarily produced during hydrocarbon oxidation, with an estimated source strength of $250 \pm 54 \mathrm{Tg} \mathrm{yr}^{-1}$ (Fortems-Cheiney et al., 2012). In the background troposphere, the oxidation of methane $\left(\mathrm{CH}_{4}\right)$ by hydroxyl radical $(\mathrm{OH})$ is the main source. Photochemical degradation of anthropogenic and biogenic hydrocarbons greatly enhances $\mathrm{HCHO}$ production in the lower troposphere, with the most significant precursor being biogenic hydrocarbon isoprene. HCHO is also emitted through fuel combustion (Olaguer et al., 2009; Luecken et al., 2012), biomass burning (Yokelson et al., 2013) and vegetation (DiGangi et al., 2011). These sources are generally minor globally compared to secondary production, but they may be significant locally. $\mathrm{HCHO}$ is lost via photolysis and reaction with $\mathrm{OH}$, with a typical daytime lifetime of 2-3 h. Wet and dry deposition are minor sinks globally, but can be significant locally, such as during precipitation. Typical mixing ratios range from tens of parts per trillion by volume (pptv) in pristine air to several hundred parts per billion by volume (ppbv) near combustion sources.

$\mathrm{HCHO}$ is a tracer for, and active participant in, multiple atmospheric processes. As a byproduct of hydrocarbon oxidation, $\mathrm{HCHO}$ can provide quantitative constraints on the photochemical link between primary emissions and secondary 
pollutants (Chatfield et al., 2010; Duncan et al., 2010). A number of studies have employed satellite-based $\mathrm{HCHO}$ observations to better constrain isoprene emission inventories (Palmer et al., 2003, 2006; Millet et al., 2008; Marais et al., 2012). Because of its short lifetime, the mixing ratio of $\mathrm{HCHO}$ in the upper troposphere is typically 10 to 100 times less than that near continental surfaces. Convection can pump surface air to the upper troposphere very rapidly, and $\mathrm{HCHO}$ is a valuable marker for the efficiency of this process (Barth et al., 2007; Fried et al., 2008) and a participant in ensuing chemistry (Apel et al., 2012). Furthermore, photolysis of $\mathrm{HCHO}$ is a potent source of radicals and thus helps to propagate chemical cycles (Edwards et al., 2011, 2013).

A handful of techniques are currently available to measure $\mathrm{HCHO}$ in the atmosphere; a review of these methods and inter-comparisons can be found elsewhere (Gilpin, et al., 1997; Cardenas et al., 2000; Hak et al., 2005; Wisthaler et al., 2008; Kaiser et al., 2014). Laser-based and spectroscopic methods are generally employed when high sensitivity and time response are required. The most common among these include tunable diode laser-based absorption spectroscopy (Weibring et al., 2007; Fried et al., 2008), differential optical absorption spectroscopy (DOAS) (Baidar et al., 2013) and laser-induced fluorescence (LIF) (Hottle et al., 2009). Diode laser spectroscopy and DOAS rely on molecular absorption in the IR and UV regions, respectively, while LIF utilizes UV-stimulated emission. DOAS can be applied for in situ or remote (column-averaged) observations, and a similar principle underlies satellite-based $\mathrm{HCHO}$ observations (Chance et al., 2000). Indeed, HCHO is one of only a few hydrocarbons observable from space, and high-quality in situ observations are critical for retrieval validation.

Instrumentation for airborne observations is held to stringent engineering standards. An ideal instrument is small, lightweight, low power, and able to withstand vibrations and large temperature variations. Low maintenance, calibration stability, and fast time response $(\geq 1 \mathrm{~Hz})$ are also desirable. For HCHO, a substantial dynamic range - roughly 4 orders of magnitude - is also necessary to adequately sample mixing ratios throughout the troposphere and lower stratosphere. Here, we present the NASA In Situ Airborne Formaldehyde (ISAF) instrument, a new LIF-based HCHO detector that meets or exceeds all of the above requirements. After a brief synopsis of the LIF method in Sect. 2, we provide a detailed description of instrument construction (Sect. 3) and performance characteristics (Sect. 4). Section 5 gives an example of observations taken during a recent field campaign.

\section{Principle of operation}

LIF is a well-established spectroscopic method for selective measurement of trace gases. LIF detection of HCHO was first reported by Becker et al. (1975) and refined by Möhlmann (1985). Hottle et al. (2009) applied the technique (a)

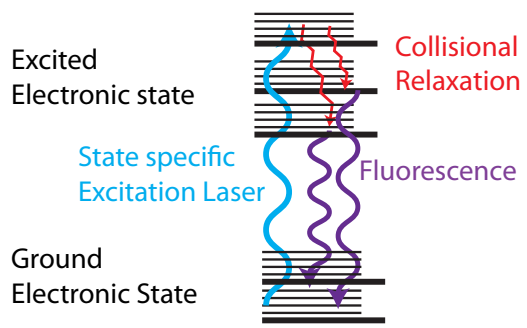

(b)

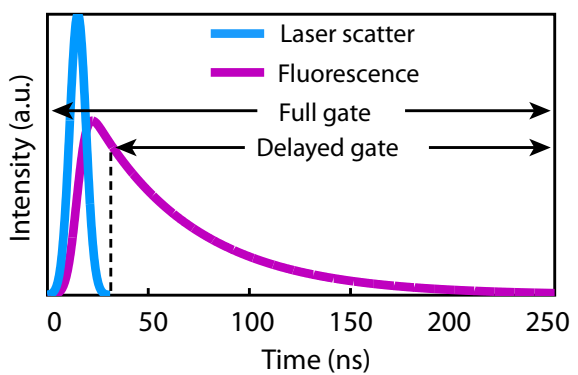

Figure 1. The spectral (a) and temporal (b) features of laser induced fluorescence detection. In (a) the laser excites a single rotational transition at $353.16 \mathrm{~nm}$. The fluorescence occurs after collisional relaxation and appears at longer wavelengths. In (b) time gating of fluorescence detection provides additional discrimination between prompt and longer timescale processes. Laser excitation and elastic scattering processes that include Raman, Rayleigh, and chamber reflections have timescales that match the laser pulse ( $25 \mathrm{~ns}$ fullwidth). Fluorescence has a lifetime of tens of nanoseconds and the signal extends for more than $100 \mathrm{~ns}$ beyond the end of the laser pulse and elastic scattering. The delayed gate captures HCHO fluorescence while the full gate captures both fluorescence and scattered light.

to in situ atmospheric measurements. In these approaches a tunable laser is used to ensure specificity to HCHO and a pulsed operation is used to minimize background noise. Figure 1 illustrates the key processes involved. A narrow-band laser, tuned to a specific rovibronic absorption line in the $353-355 \mathrm{~nm}$ region of the $A-X$ electronic transition, promotes a fraction of the HCHO molecules to the first excited electronic state. The majority of these excited HCHO molecules are quenched back to the ground electronic state by collisions with air. A small fraction $(\sim 1 \%)$ undergo vibrational relaxation and subsequently relax to the ground electronic state through fluorescence, emitting a structured band of photons in the range of 400-470 nm (Becker et al., 1975; Shibuya et al., 1979; Möhlmann, 1985). Fluorescence occurs with an exponential decay over several hundred nanoseconds (Fig. 1, right). The number of fluorescence photons per unit of laser power is proportional to the mixing ratio of $\mathrm{HCHO}$ in the sample gas. This relationship is readily quantified with a known standard.

For ISAF, the chosen absorption feature is centered at $353.163 \mathrm{~nm}$, which has a cross-section of $3.77 \times 10^{-19} \mathrm{~cm}^{2}$ at 150 Torr (Co et al., 2005). While this cross-section is 
$\sim 7 \%$ lower than the peak value in this band, it is chosen because of the presence of several unique adjacent peaks, notably a triplet feature (see Fig. 6). This area of the spectrum serves as a "fingerprint" for HCHO, simplifying the wavelength-tracking algorithm. The offline position is only $0.005 \mathrm{~nm}$ away from the peak. This wavelength difference provides a high differential cross-section for $\mathrm{HCHO}$, but the differential is negligible for species that have non-structured absorptions in this region. This allows for precise and selective measurements of HCHO. To date, we have not identified any interfering species that has a measurable differential absorption and fluorescence between the online and offline positions.

\section{Instrument description}

ISAF is comprised of four main subsystems: a UV fiber laser, an optical bench comprising the detection and reference cells, gas handling components (pressure controller, inlet system, tubing, valves and pump), and the data acquisition computer. Each of these subsystems is described in greater detail below. Aside from the vacuum pump, all components are contained in a single custom-built chassis with dimensions of $60 \mathrm{~cm}$ length $\times 43 \mathrm{~cm}$ width $\times 35 \mathrm{~cm}$ height. The layout of the chassis is shown in Fig. 2. This chassis is designed to run on $28 \mathrm{~V} \mathrm{DC}$, which is supplied directly from aircraft power or through an external AC/DC interface unit. The instrument itself weighs $25 \mathrm{~kg}$ and draws $200 \mathrm{~W}$. An external pump, computer, and control box are used for operation on larger aircraft with on-board operators. Including all peripherals, the total instrument package weighs $60 \mathrm{~kg}$ and draws a peak power of $600 \mathrm{~W}$.

\subsection{Laser}

Pulsed, tunable UV laser radiation is provided by a NovaWave (now Thermo Scientific) TFL 3000 fiber laser. The laser uses a master oscillator power amplifier architecture to provide narrow wavelength, tunable, pulsed light at $353 \mathrm{~nm}$. A single distributed feedback laser operating at $1060 \mathrm{~nm}$ is chopped with an acousto-optic modulator and amplified in two stages to $2 \mathrm{~W}$ with a series of diodepumped, semiconductor-doped, polarization-maintaining optical fibers. The $1060 \mathrm{~nm}$ output is fiber-coupled into a harmonic generation module containing two periodically poled nonlinear crystals and collimating optics. The harmonic generation housing is mounted on the optical bench (Fig. 2) and coupled with free-space optics. The repetition rate is $300 \mathrm{kHz}$, with a pulse width of $25 \mathrm{~ns}$ and a typical output power of $10-40 \mathrm{~mW}$. The output wavelength is tunable to $\sim 0.0001 \mathrm{~nm}$, permitting resolution of individual rovibronic absorption features. Computer control is provided via RS232. The entire unit weighs $\sim 12 \mathrm{~kg}$ and draws $<60 \mathrm{~W}$,

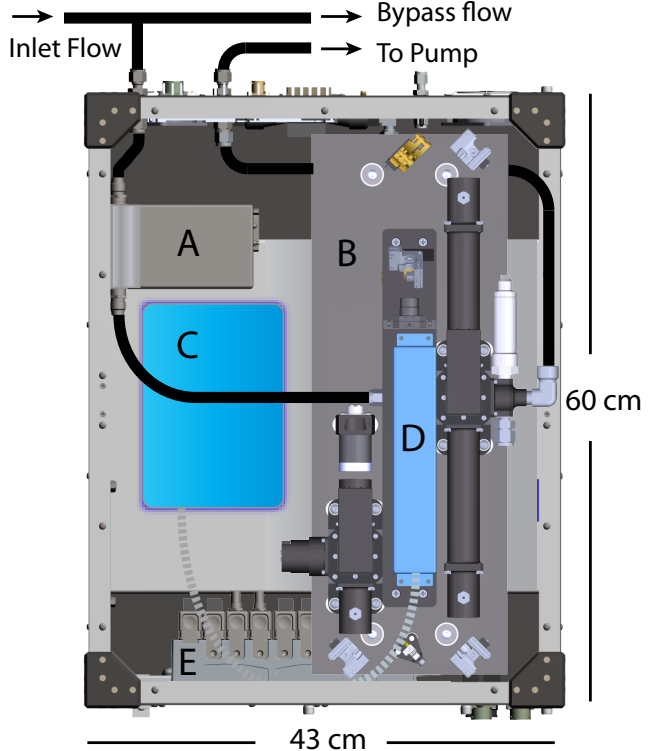

Figure 2. A top view of the ISAF instrument layout. The instrument chassis is $60 \times 43 \times 35 \mathrm{~cm}$ and $25 \mathrm{~kg}$. The major subsystems are labeled: (A) pressure controller, (B) optical bench, $(\mathrm{C})$ tunable fiber laser, (D) harmonic generation housing, and (E) data acquisition system.

making it an attractive alternative to larger laser systems typically used for LIF.

\subsection{Optical bench}

The optical bench is shown in greater detail in Figs. 3 and 4. The bench is an aluminum sandwich panel with $1.25 \mathrm{~cm}$ thick honeycomb core and with $0.1 \mathrm{~cm}$ cladding. The bench is mounted to the instrument chassis with vibration damping mounts (Sorbothane) to minimize vibrations. Figure 3 shows the optical bench and the path of the laser and gas flow. Figure 4 shows a cross-sectional view of the detection cell. The simplicity and single-laser pass design of this system is a major advantage for field applications; alignment rarely degrades throughout flight campaigns or during shipping. Likewise, the instrument shows no effects in high vibration environments or in aircraft maneuvers. Both cells are heated to a constant temperature of $35^{\circ} \mathrm{C}$, and capability exists to heat other parts of the instrument if needed (i.e., for high-altitude applications).

UV laser light is collimated at $2 \mathrm{~mm}$ diameter at the output of the harmonic stage with a lens (Thor LA4600UV, $f=100 \mathrm{~mm}$ ) and directed to the detection cell via four dielectric-coated mirrors (Edmund 47-323). Two of these mirrors, along with the two between the detection and reference cells, utilize piezo-driven mounts (Newport Agilis) for remote alignment. The laser beam enters and exits the reduced-pressure detection cell (Fig. 4) through V-type antireflection-coated fused silica windows (Edmund 48-207) 


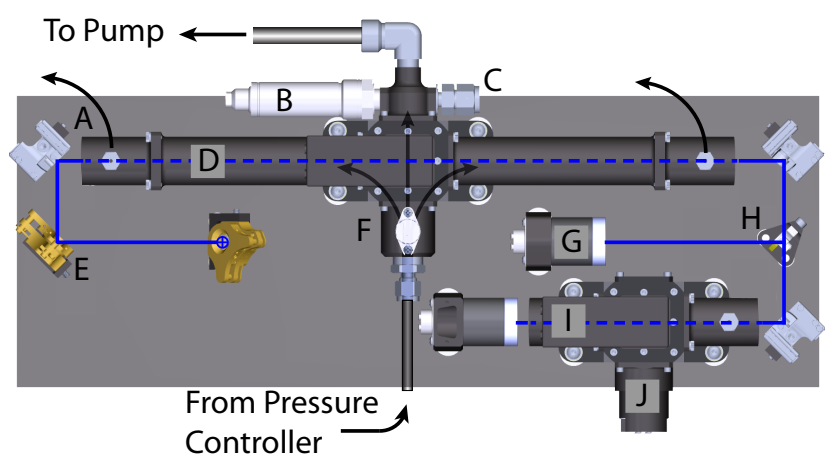

Figure 3. This diagram shows a top view of the optical bench with the harmonic generation housing and platform removed. The laser propagation is indicated by the solid (open to air) and dashed (inside the cells) blue lines. The sample flow is indicated by the black arrows. The components are (A) piezo actuated mirror (3); (B) pressure sensor; (C) thermistor; (D) sample detection cell; (E) fixed mirror; (F) sample heater; $(\mathrm{G})$ reference cell (2); (H) beam splitter; (I) reference cell; (J) formaldehyde source.

tilted at $5^{\circ}$ to redirect reflections from the window surfaces out of the beam propagation path. The arms of the detection cell contain a series of circular baffles with $2.5-3.5 \mathrm{~mm}$ apertures to eliminate stray light. Baffles and cell walls are coated with a combination of Avian black paint (Avian Technologies), black anodize, and molybdenum oxide treated aluminum (Insta-Black 380, EPI). The innermost baffles are coated with an ultra-black custom carbon nanotube treatment (Hagopian, 2011). The laser beam, gas flow, and focus of the collection lens intersect orthogonally in the center of the cell. Along this detection axis, photons are imaged with an aspheric lens (Edmund 6-321) through a $370 \mathrm{~nm}$ long pass absorption filter (Edmund 66-049) and a $400 \mathrm{~nm}$ long pass interference filter (Omega 3RD400LP). The image is partially focused with another lens (Thor LA1608, $f=75 \mathrm{~mm}$ ) onto a photomultiplier tube (PMT) (Hamamatsu 7360). A spherical mirror (Thor CM254, $f=25 \mathrm{~mm}$ ) is located opposite the aspheric lens to improve collection efficiency. Since this is a fluorescence measurement, only the sample inside the imaging volume of the collection lens (the center of the cell) is detected.

After the detection cell, a beam sampler (Thor BSF05-UV) diverts $\sim 4 \%$ of the laser to a power monitor comprised of a diffuser (Thor DGUV10-600), filter (Thor FGUV11), and amplified photodiode (OSI 555-UV). The photodiode has a large active area $\left(1 \mathrm{~cm}^{2}\right)$ to ensure that the entire laser beam is detected. The diffuser is needed to spread the laser over enough of the photodiode to avoid inhomogeneities in the photodiode responsivity. The main laser beam is directed into a reference cell (Fig. 3, lower right), which is used to monitor the laser wavelength. This cell is nearly identical to the sample cell shown in Fig. 4; the main differences are shorter arms and a neutral density filter (Thor NE30A) to limit fluorescence signal intensity. A heated cartridge filled with pow-

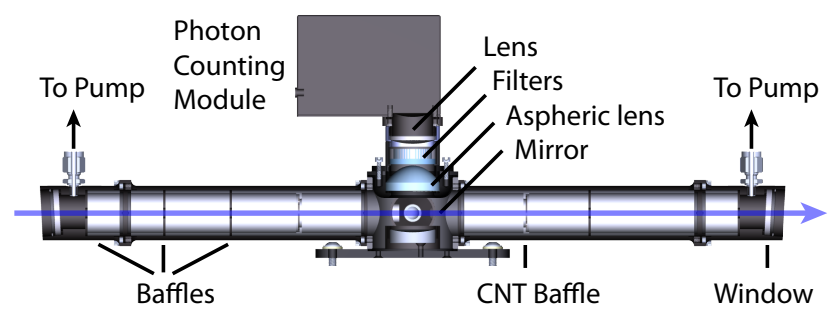

Figure 4. This diagram shows a side-view of the cross-section of the detection cell. The blue line indicates the laser path and propagation direction.

dered urea formaldehyde glue (DAP Weldwood) provides a large concentration of $\mathrm{HCHO}(\sim 1 \mathrm{ppmv})$. This cell is static (no gas flow) but is maintained at the same pressure as the sample cell by coupling the arms to the sample cell exhaust. This is critical for maintaining the same absorption line width in both cells, as the reference cell signal is used to correct sample cell data (see Sect. 3.5). A normally closed solenoid valve and an activated charcoal scrubber are placed inline to limit sample cell contamination. The laser beam is ultimately dumped into a second power monitor, which is primarily used to gauge laser alignment.

\subsection{Gas handling}

The primary components of the air sampling system include the aircraft inlet, pressure controller, and vacuum pump. Some care must be taken with the inlet system to minimize adsorption and production/loss of HCHO on surfaces (Wert et al., 2002). Outgassing of HCHO from tubing walls, physisorption and desorption of $\mathrm{HCHO}$, and the chemical or catalytic conversion of oxygenated hydrocarbons on metal surfaces to $\mathrm{HCHO}$ are primary concerns in the design of the sampling system. Fast flows, low surface area fluorocarbon or fluorocarbon-coated surfaces, and minimal dead space are the design features. For example, there are no valves or sensors between the tip of the inlet and the instrument; the sampling path is continuous tubing with VCO (Swagelok) fittings. Furthermore, all metal surfaces are coated with fluorocarbon (FluoroPel, Cytonix), all tubing is PTFE or FEP, and pressure, temperature, and flow are measured after the detection cell.

Figure 5 depicts the inlet design used on the NASA DC-8 aircraft. The inlet tube is a $45 \mathrm{~cm}$ length of $0.48 \mathrm{~cm}$ ID Silcosteel (Restek) coated with FluoroPel mounted at $90^{\circ}$ to the airflow to reject particles. The tip of the inlet is chamfered at $15^{\circ}$ to enhance the particle rejection and is heated to 30 $60^{\circ} \mathrm{C}$ inside the winglet to prevent condensation and sticking. A tapered aluminum nacelle oriented parallel to the direction of flight serves as a flow straightener and generates a ram pressure equal to $\sim 1.15$ times that of ambient at the inlet tip, driving an air flow of 10-25 sLm through the inlet. The corresponding volumetric flow at typical pressures and tem- 


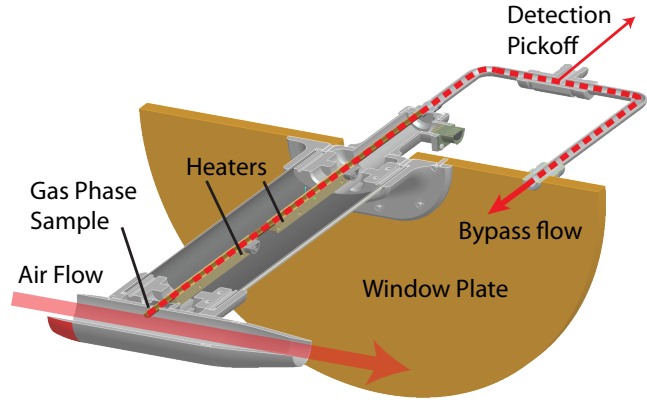

Figure 5. This diagram shows a cross-section view of the particle rejection inlet mounted on a window plate. A ram air nacelle mounted on an airfoil $30 \mathrm{~cm}$ from the plate generates ram pressure that directs the ambient air through the heated tube mounted at $90^{\circ}$ to the flow. A small fraction $(2 \mathrm{sLm})$ of the heated air enters the instrument and the remainder $(\sim 20 \mathrm{sLm})$ returns to ambient. The plumbing on the cabin side of the window plate is not drawn to scale. There is $1 \mathrm{~m}$ of tubing between the inlet and detection pickoff.

peratures is $25-65 \mathrm{~L} \mathrm{~min}^{-1}$. Inside the aircraft, air is carried via $1 \mathrm{~m}$ of $0.7 \mathrm{~cm}$ ID PTFE tubing to the instrument chassis and is sub-sampled at $2-4 \mathrm{sLm}$. The excess flow passes through a flow meter (Honeywell) and exits behind the inlet. The residence time in the heated Silcosteel portion of the tube is $8-20 \mathrm{~ms}$, with an additional $35-100 \mathrm{~ms}$ in the transfer tubing.

Inside the chassis, sample air passes through a pressure controller (MKS 640A) heated to $35^{\circ} \mathrm{C}$, followed by a $\sim 20 \mathrm{~cm}$ length of $0.4 \mathrm{~cm}$ ID PFA tubing connected to the detection cell. The residence time in the detection cell is $\sim 115 \mathrm{~ms}$. Sample pressure, temperature, and flow rate are monitored immediately downstream of the cell to minimize surface area. A small amount of sample air $\left(\sim 100 \mathrm{~cm}^{3} \mathrm{~s}^{-1}\right)$ is drawn through the laser arms to reduce contamination from painted surfaces or dead space. Sample air is exhausted through the vacuum pump (Agilent IDP-3 or Vacuubrand MD-1). During instrument shutdown, contamination is minimized by backfilling the cell with ambient air scrubbed by a Drierite/molecular sieve cartridge, which reduces HCHO to $<100$ pptv.

\subsection{Data acquisition}

All hardware interfacing is handled with an all-solid-state CompactRIO (National Instruments) with realtime operating system and a field programmable gate array (FPGA). The FPGA and acquisition software are configured for fast photon counting and autonomous operation. Six $200 \mathrm{MHz}$ counters are used to integrate PMT signals at a nominal rate of $10 \mathrm{~Hz}$. Pulses from the sample cell PMT are sampled by three of these counters, one non-gated (continuous) and two each with a separate gate (Fig. 1, right). The "full" gate samples both scattered laser light and $\mathrm{HCHO}$ fluorescence, while the

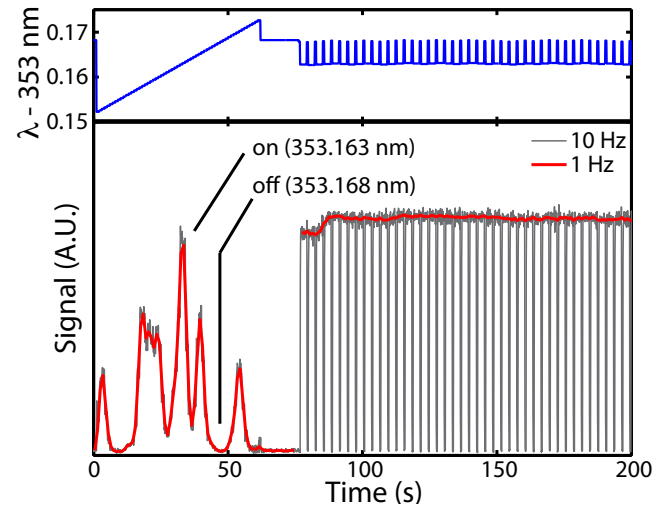

Figure 6. These plots show the wavelength (top) and fluorescence signal (bottom) during a scan of the laser, followed by the standard data acquisition mode. The computer algorithm uses the reference cell signal to maintain the laser on the large rotational feature at $353.163 \mathrm{~nm}$. The contributions of species other than HCHO to the fluorescence signal are removed by subtracting the signal at the offline position. The difference between the signal at the online position and the offline position is proportional to [HCHO].

"delayed" gate excludes the laser. The reference cell gate is the same width as the full gate. Laser power is also monitored at $10 \mathrm{~Hz}$. Other diagnostics (laser parameters, temperature, pressure, flow, GPS, and aircraft data) are recorded at $1 \mathrm{~Hz}$.

Figure 6 illustrates the standard data acquisition routine. Online counting is done for $2.5 \mathrm{~s}$ ( 25 points), followed by $0.5 \mathrm{~s}$ (5 points) offline. Laser drift (mainly due to temperature of the seed laser diode) requires an active line-locking algorithm. The online position is alternately shifted to a slightly $( \pm 0.0001 \mathrm{~nm})$ lower or higher wavelength on adjacent online cycles, and the reference cell is monitored for maximum signal. When the laser is tuned precisely to the online position the reference cell is at the maximum signal. When the laser is tuned $0.0001 \mathrm{~nm}$ (or $0.0002 \mathrm{~nm}$ ) off of the peak position the signal drops by about $\sim 5 \%$ (or $\sim 10 \%$ ). The resulting small changes in the reference cell signal are used to maintain the laser on the peak of the line. The signal is also used to correct the sample signal by the $\sim 5 \%$ (or $\sim 10 \%$ ) needed to normalize the signal to the signal at the peak position.

Once per hour, a full scan over the HCHO fingerprint is recorded. This is primarily used to optimize the harmonic generation crystal temperatures and as a performance diagnostic. For example, the presence of interfering species can be detected in the spectrum. To date, we have not detected any features other than those shown in Fig. 6. This is not surprising. To be detected, the potential species must absorb at $353.163 \mathrm{~nm}$, fluoresce in the $400-470 \mathrm{~nm}$ band, and have a significant fluorescence lifetime. 


\subsection{Data reduction}

Both the full and delay gate signals can be used to derive HCHO mixing ratios. The delay gate excludes $\sim 53 \%$ of the fluorescence signal, but it is also relatively insensitive to laser scatter (from Raman, Rayleigh, or particulates) and gives superior signal / noise $(\mathrm{S} / \mathrm{N})$ ratios below $\sim 550 \mathrm{pptv}$ HCHO. Thus, the delay gate signal is typically used, and all results discussed below stem from this signal. The full gate data provides a useful metric for scatter and other potential laser-related issues.

The detected signal is proportional to the abundance of $\mathrm{HCHO}$ and the laser power. To the first order, we can determine $\mathrm{HCHO}$ from the ratio of the laser power-normalized difference between the online and offline signals and the calibration factor. To minimize systematic noise, however, we use additional steps to convert raw counts to mixing ratios. These analysis steps are (1) normalization by laser power; (2) background subtraction, determined by a smoothed interpolation of offline signals; (3) normalization by the reference cell signal to account for deviations from the maximum absorption wavelength due to the line-locking algorithm; and (4) application of a pressure-dependent calibration factor (see Sect. 4.1).

\section{Performance}

\subsection{Sensitivity}

Detection sensitivity (signal response per unit of $\mathrm{HCHO}$ ) is a function of laser power, collection efficiency, PMT response, and counter gating. As mentioned above, signals are normalized by laser power. Because of the single-pass design, laser alignment does not affect sensitivity except in extreme cases when the laser is partially blocked. In practice, the laser maintains alignment for entire field campaigns and usually during shipments to and from deployment locations. During flight, the ratio of the two power monitors (at the exits of the detection and reference cells) is constant to $\pm 3 \%$.

Collection efficiency depends on the physical characteristics of the sample cell, including the types of collection optics (lenses and filters) and their relative spacing. We do not expect the collection efficiency to change under normal operation. However, catastrophic events, such as the degradation of optics from contamination could reduce the sensitivity. The responsivity of the PMT should be stable in the short term (months to years), but it can degrade over the lifetime of the PMT. The gated counter timing is a fixed parameter and is optimized for signal / noise. Changes in the gate timing relative to the laser pulse could affect the sensitivity. These changes are easily diagnosed in data reduction and can be corrected by using the non-delayed gates.

In practice, instrument sensitivity is determined via calibration against a primary standard, consisting of a 500-
700 ppbv mixture of HCHO in $\mathrm{N}_{2}$ (Scott Gas/Air Liquide). This mixture is calibrated every few months (typically before and after a field deployment) with an MKS Multigas 2031 Fourier transform infrared spectrometer using manufacturerprovided IR cross-sections tied to gravimetric permeation tube calibrations. The $1 \sigma$ uncertainty in mixing ratio from any single determination is typically $2-3 \%$. $\mathrm{HCHO}$ mixtures are also stable over time; for example, five calibrations performed on a single tank over the course of a year give a mixing ratio of $611 \pm 8 \mathrm{ppbv}$ and show no trend.

To better constrain the calibration to literature standards, a series of experiments were performed to compare concentrations derived from Fourier transform infrared spectroscopy (FTIR) and long-path UV absorption. The UV absorption cell was a custom-built, $200 \mathrm{~cm}$ long, $1.1 \mathrm{~cm}$ diameter stainless-steel tube fitted with windows, gas ports, and a pressure gauge. Visible light from a Cathodeon deuterium lamp was filtered (Edmund U-330) and focused through the cell and measured with an Ocean Optics Maya 2000 spectrometer. The cell pressure was held above atmosphere (11101150 Torr) with a gas flow rate of $6 \mathrm{sLm}$. Absorption measurements were carried out simultaneously in both the IR and UV systems using a high concentration (nominally $11 \mathrm{ppmv}$ ) HCHO standard. Literature UV cross-sections (Meller and Moortgat, 2000) in the $285-370 \mathrm{~nm}$ range were fit to the measured absorption spectra (nominal resolution $\sim 1 \mathrm{~nm}$ ) to obtain $\mathrm{HCHO}$ concentrations and mixing ratios. Based on 11 such experiments, the mixing ratios from UV and IR are $10.49 \pm 0.20 \mathrm{ppmv}$ and $10.96 \pm 0.02 \mathrm{ppmv}$, respectively. The ratio of $\mathrm{UV} / \mathrm{IR}=0.9571$ is applied to all IR-derived values; for example, the IR-derived average mixing ratio of $611 \mathrm{ppbv}$ is corrected to $585 \mathrm{ppbv}$. By making this adjustment, our calibration is tied to the Meller and Moortgat (2000) crosssection rather than the MKS spectrometer.

Calibrations of ISAF are achieved via standard additions to zero air. Zero air is delivered either from an ultra zero air cylinder or from a zero air generator (Sabio 2020) with an additional Drierite/molecular sieve scrubber to reduce $\mathrm{HCHO}$ mixing ratios to $30 \mathrm{pptv}$ or less. Small flows of the primary HCHO standard $\left(1-50 \mathrm{~cm}^{3} \mathrm{~s}^{-1}\right)$ are diluted into a $5 \mathrm{sLm}$ flow of zero air to yield $\mathrm{HCHO}$ concentrations in the range of 0 5 ppbv. Signal is plotted against the diluted HCHO mixing ratio, and the slope of this relationship gives the instrument sensitivity (see inset of Fig. 7). This sensitivity varies with sample cell pressure due to the combined effects of number density, absorption line broadening, and quenching. Figure 7 shows this pressure dependence as determined from a number of standard addition experiments. Peak sensitivity occurs at a cell pressure of $200 \mathrm{mbar}$. In flight, the system is configured to maintain a constant pressure that is dictated by the ceiling of the aircraft. For example, on the NASA DC-8, the cell pressure is typically held at $100 \mathrm{mbar}$, and the sensitivity is 75 counts s $\mathrm{mW}^{-1} \mathrm{ppbv}^{-1}$. Propagation of uncertainties in the $\mathrm{HCHO}$ concentration, determined by both the absolute 


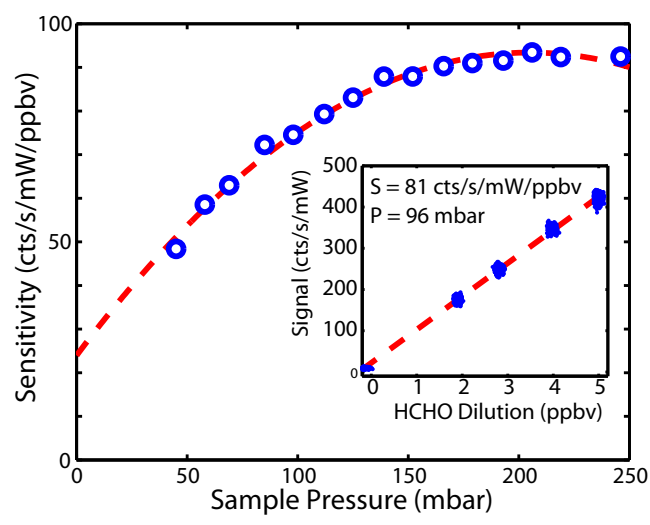

Figure 7. This plot shows the sensitivity of the instrument to $\mathrm{HCHO}$ versus pressure. The inset shows an example of a calibration using an HCHO standard addition to a flow of air. Several calibrations at one pressure are used to determine the pressure dependence.

UV absorption measurement and dilution flow rates, gives an estimated accuracy of $\pm 10 \%$.

Calibrations are generally carried out in the laboratory both before and after field missions. Because $\mathrm{HCHO}$ adheres to surfaces in tubing, fittings, regulators and flow meters, several days are needed to ensure consistent results, especially with new PTFE or FEP tubing. Calibrations can be performed in the field during campaigns, if needed. In practice, these calibrations are used to monitor instrument performance. We have never changed the instrument sensitivity calibration numbers during a campaign. Based on four field campaigns spanning 2 years, sensitivity varies by less than $10 \%$ over a single mission and by less than $30 \%$ between missions. Given the difficulty of adding a known amount of $\mathrm{HCHO}$, it is likely that the sensitivity of the instrument was constant over those 2 years and that the variability in the calibrations is due to differences in calibration conditions and personnel.

\subsection{Precision}

The instrument precision is primarily limited by processes that generate noise or affect the background (offline) signal. The largest potential sources of noise, Rayleigh and Raman scattering of laser light, are reduced with a combination of optical filters, absorbing surfaces (e.g., baffles), and gated photon counting. Laboratory tests indicate that scattering contributes less than 7 counts $\mathrm{s}^{-1} \mathrm{~mW}^{-1}$ to the background signal at 100 mbar.

Figure 8 shows the short-term precision estimated from the normalized standard deviation $\left(\sigma_{x} /<x>\right)$ for data segments of 10 to $15 \mathrm{~min}$ at a range of constant mixing ratios. Also displayed is the inverse square root dependence expected from Poisson counting statistics. Above mixing ratios of $\sim 100 \mathrm{pptv}$, the precision is better than $20 \%$ and exhibits the expected slope but is somewhat higher than the Poisson

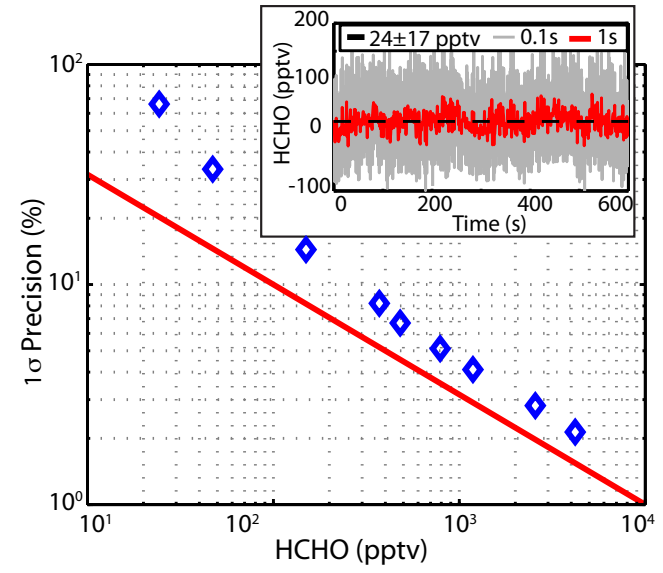

Figure 8. This plot shows the measured and theoretical $1 \sigma$ precision as a percentage of $\mathrm{HCHO}$ concentration. The inset shows an example of the mean and standard deviation for constant HCHO. The average value (24 pptv) and the standard deviation (17 pptv) are used to determine the measured precision ( $70 \%$ in this case) shown by the blue diamonds. The solid line is the theoretical maximum precision based on the counting statistics of the signal level.

limit. Some fraction of this offset is due to uncertainty in the background. This would also explain the reduced precision observed at the lowest mixing ratios. It is also likely that some "extra" variability is contributed by the calibration gas addition system, which would be directly proportional to the HCHO mixing ratio. We note that small changes in room temperature can cause small fluctuations in the amount of $\mathrm{HCHO}$ added to the calibration gas flow, presumably from increased or decreased desorption of HCHO from surfaces (i.e., regulator, valves, flow meters, and fittings). The true instrument precision thus lies between the measured and predicted values in Fig. 8.

In theory, time-averaging will improve instrument precision. Figure 9 shows the mean-normalized Allen deviation for $60 \mathrm{~min}$ of sampling at a constant mixing ratio of $5.1 \mathrm{ppbv}$. At short averaging times, precision improves as the inverse square root of integration time, consistent with white noise as the dominant source of variability. Averaging from the native data rate of $0.1 \mathrm{~s}$ to the typical reporting interval of $1 \mathrm{~s}$ improves precision by a factor of 3 . Averaging to the "optimal" interval of $130 \mathrm{~s}$ improves precision by a factor of 18 , although natural variability would likely dominate on this timescale in the real atmosphere.

\subsection{Detection limit}

For counting statistics, the signal / noise ratio is defined as

$\frac{S}{N}=\frac{p C_{\mathrm{f}}[\mathrm{HCHO}]_{t}}{\sqrt{p C_{\mathrm{f}}[\mathrm{HCHO}] t+2 p B t}}$,

where $p$ is laser power, $C_{\mathrm{f}}$ is the calibration factor (sensitivity), $[\mathrm{HCHO}]$ is the mixing ratio, $B$ is the background count 


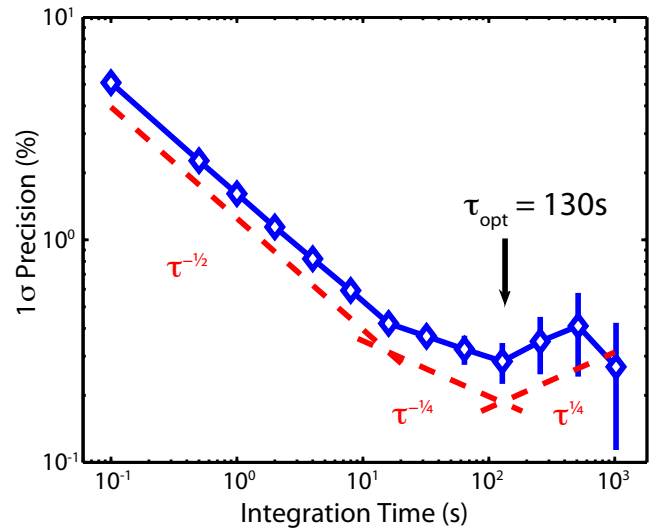

Figure 9. The mean normalized Allen deviation is shown for $60 \mathrm{~min}$ of sampling at a constant $\mathrm{HCHO}$ concentration of $5.1 \mathrm{ppbv}$. The short integration times show a $\tau^{-1 / 2}$ increase in precision, consistent with white noise.

rate, and $t$ is the integration time. For a typical laser power of $10 \mathrm{~mW}$, a sensitivity of 75 counts s $\mathrm{mW}^{-1} \mathrm{ppbv}^{-1}$, a background count rate of 8 counts $\mathrm{s}^{-1} \mathrm{~mW}^{-1}$, and an integration time of $1 \mathrm{~s}$, the estimated detection limit is $18 \mathrm{pptv}$ for $\mathrm{S} / \mathrm{N}=1$ or $36 \mathrm{pptv}$ for $\mathrm{S} / \mathrm{N}=2$. This value agrees well with the $1 \sigma$ variability of $17 \mathrm{pptv}$ observed at low mixing ratios (inset of Fig. 8). Time averaging will improve the detection limit in proportion to the precision (Fig. 9). The detection limit scales as the inverse square root of laser power. The laser is capable of producing as much as $40 \mathrm{~mW}$ of power; thus, ISAF can potentially achieve a factor of two reduction in the detection limit by operating at higher laser power. For example, the instrument operated at $20 \mathrm{~mW}$ during its first deployment and achieved higher S / N. More recently, however we choose to operate at reduced power $(10 \mathrm{~mW})$ to extend the life of the laser diodes and nonlinear crystals.

The inset of Fig. 8 is a typical example of the signal measured with zero air added to the calibration system. Zero air and ultra zero air have 20-50 pptv $\mathrm{HCHO}$, but we can obtain lower values by passing the air through a molecular sieve. With clean FEP or PFA tubing, measurements of zero or near-zero are easily obtained, even after exposure to 10 or $20 \mathrm{ppbv}$ of HCHO. The ISAF instrument has no measurable chemical offset or bias of $\mathrm{HCHO}$ and shows little if any "memory" of exposure to high concentrations of $\mathrm{HCHO}$ (see Sects. 4.4 and 4.5 for more detail). However, the uncertainty shown in the inset of Fig. 8 is typical at these low concentrations. At very low fluorescence photon count rates, small changes in the laser scatter between the online and offline position can lead to an offset in the measurement. This is because we assume that the laser scatter is equal at the online and offline wavelengths. Though the wavelength difference is small $(0.005 \mathrm{~nm})$ there is some laser pointing change due to walk-off in the harmonic generation stage between these wavelengths, and potentially a small difference in laser scat-

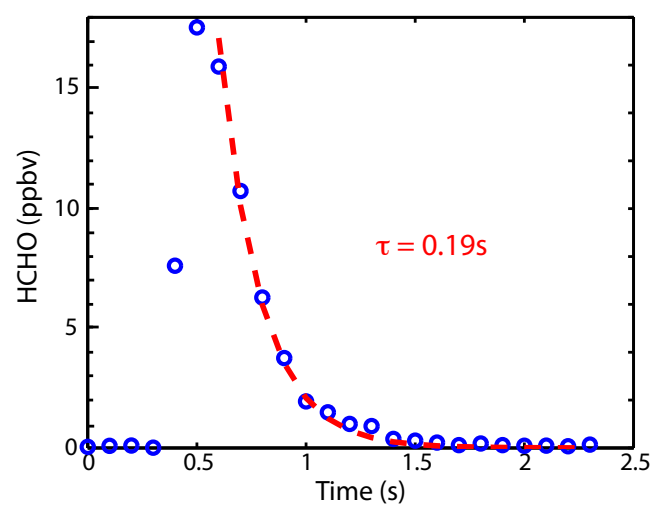

Figure 10. The time response of the instrument is demonstrated with a $10 \mathrm{~ms}$ pulse of $\mathrm{HCHO}$ added to the sample air flow in the lab. The measured HCHO shows the rapid rise expected with the flush time of $\sim 115 \mathrm{~ms}$. The decay of $190 \mathrm{~ms}$ indicates second-order effects such as wall interactions and the presence of small volumes with longer flush times.

ter. This difference can result in a negative or positive offset. We assign an uncertainty of \pm 10 pptv to account for this potential offset.

\subsection{Time response}

Though the nominal sampling frequency is $10 \mathrm{~Hz}$, the flush time of sampling volumes can limit the effective instrument time response. Minimizing the response time is critical for applications that require measurements of fast changes in concentration, such as eddy covariance and sampling of discrete plumes and for eliminating contamination from exposure to high concentrations of HCHO. For typical inlet pressures and flow rates, the plug-flow transit time from the tip of the inlet to the instrument chassis is $43-120 \mathrm{~ms}$. This creates a delay between sampling and detection but should not cause significant "smearing" of concentration fluctuations, as the flow is typically turbulent (Re 3000-6000). Such smearing can, however, occur in the pressure controller and sample cell. Based on the internal cell volume of $60 \mathrm{~cm}^{3}$ and a typical volumetric flow rate of $31 \mathrm{~L} \mathrm{~min}^{-1}(2.75 \mathrm{sLm}$ at $100 \mathrm{mbar}$ and $35^{\circ} \mathrm{C}$ ), the expected $1 / e$ cell flush time is $115 \mathrm{~ms}$. Figure 10 shows the instantaneous response to a $10 \mathrm{~ms}$ pulse of $\mathrm{HCHO}$, delivered via a fast switching valve (IEP series, The Lee Company). The observed decay time is $190 \mathrm{~ms}$, somewhat slower than that predicted from flow characteristics. The extra delay is likely due to the pressure controller, which acts as a critical orifice and adds to the internal volume of the sampling system. A faster time response can be achieved by increasing the flow rate through the sample cell, which depends on the conductance of the pressure controller and the pumping speed.

The fast time response is an important feature of contamination-free detection at low concentrations of $\mathrm{HCHO}$. HCHO continuously adsorbs and desorbs from sur- 


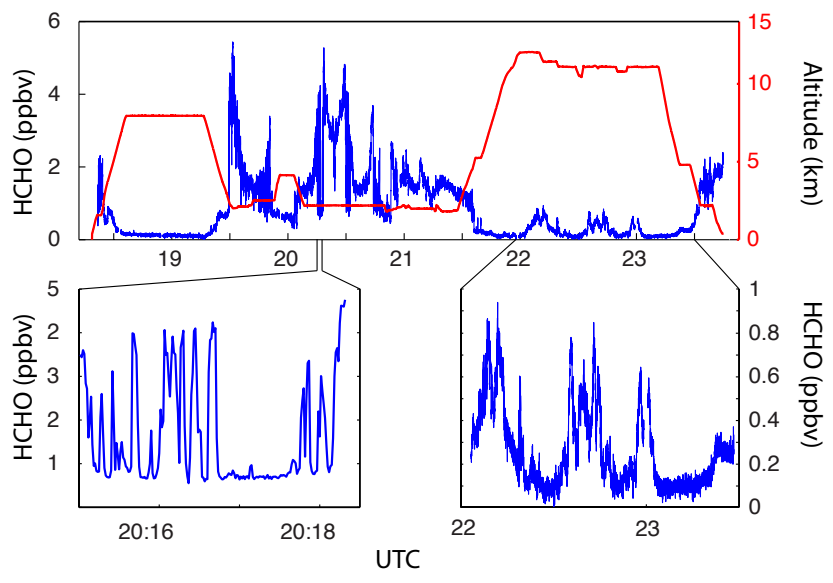

Figure 11. In situ measurements of $\mathrm{HCHO}$ are shown for the flight of 2 June on the NASA DC-8 during the Deep Convective Clouds and Chemistry (DC3) campaign in 2012. The top shows $1 \mathrm{~s} \mathrm{HCHO}$ and GPS altitude. The lower portions are expanded views of the boundary layer (BL) leg and the upper tropospheric (UT) leg. The fast response to large changes in ambient $\mathrm{HCHO}$ are evident in the BL leg. The sensitivity (better than $20 \mathrm{pptv} \mathrm{s}^{-1}$ ) is evident in the UT leg.

faces inside the instrument sampling system. This reversible process can lead to biases, especially when low concentrations are sampled after exposure of the instrument to very high concentrations. The effects of reversible adsorption and desorption of $\mathrm{HCHO}$ from surfaces is minimized by having a large mass flow, small volumes, and low surface area, the same features that lead to the fast time response. The measured time response includes both the effects of volumetric displacement and adsorption/desorption. The impact on in situ measurements is demonstrated in Sect. 4.5.

\subsection{Field demonstration}

As of March 2014, ISAF had flown successfully on four field missions spanning three platforms and a wide range of chemical conditions. For many of these flights, the instrument has flown autonomously, without an operator. Figure 11 presents observations from a single flight on the NASA DC-8 during the Deep Convective Clouds and Chemistry (DC3) experiment, which took place over the central US in May and June 2012 (Barth et al., 2015). On this flight, the DC-8 sampled at altitudes of $0-12 \mathrm{~km}$, with $\mathrm{HCHO}$ mixing ratios ranging from 50-5500 pptv. The expanded views in Fig. 11 show a boundary layer leg and an upper tropospheric leg to illustrate the time response, dynamic range and sensitivity of ISAF. During DC3, ISAF was flown simultaneously with a well-established instrument, the University of Colorado DFGAS (Difference Frequency Generation Absorption Spectrometer) (Weibring et al., 2007). Preliminary analysis indicates excellent agreement between these two instruments,

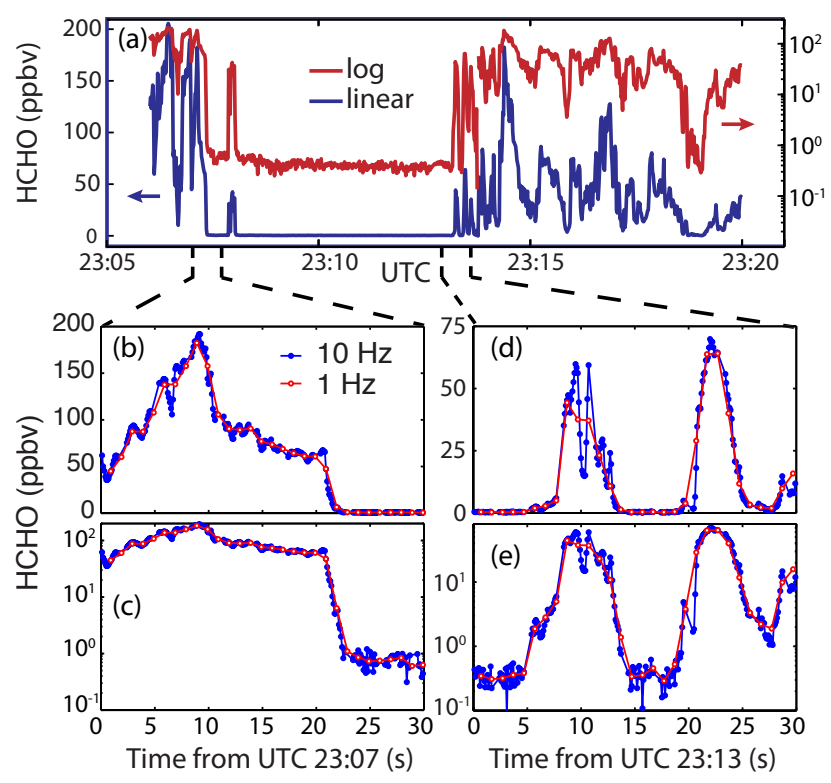

Figure 12. The time series obtained during the SEAC4RS campaign on the NASA DC-8 on 26 August 2013. The panel (a) shows the $\mathrm{HCHO}$ measured at a constant pressure altitude of $5 \mathrm{~km}$ as the DC-8 sampled the plume from the Rim Fire in Stanislaus National Forest as the plume traveled eastward over California and Nevada. Note the linear and logarithmic scaling. Panels (b) and (c) show a window of $30 \mathrm{~s}$ starting at 23:07 UTC expanded with data averaged at 10 and $1 \mathrm{~Hz}$ for linear and logarithmic scaling. Panels (c) and (d) show the same for the $30 \mathrm{~s}$ window starting at 23:13 UTC.

and a rigorous inter-comparison will be the subject of a future publication.

The time response of the instrument in flight is illustrated in Fig. 12. These data were obtained during the Studies of Emissions and Atmospheric Composition, Clouds and Climate Coupling Regional Surveys (SEAC4RS) campaign in 2013. During this flight on 26 August, the DC- 8 sampled the smoke plume from the Rim Fire in Stanislaus National Forest as it passed from California to Nevada. In this plume, measured at a constant pressure altitude of $5 \mathrm{~km}$, the $\mathrm{HCHO}$ abundance reached over 200 ppbv. The data is shown in linear and $\log$ scale to illustrate the several orders of magnitude change in $\mathrm{HCHO}$ during this segment. The observations demonstrate the ability of ISAF to measure low concentrations of HCHO even after exposure to very high concentrations for several minutes.

The expanded views provide $30 \mathrm{~s}$ snapshots of two regions where the abundance of $\mathrm{HCHO}$ is highly variable. The $10 \mathrm{~Hz}$ data is shown along with the $1 \mathrm{~Hz}$ data to demonstrate the fast response of the instrument. These $10 \mathrm{~Hz}$ data show much more structure than the $1 \mathrm{~Hz}$ and at the edges of plume filaments the transitions are much steeper. For example, the edge of the plume at time $=22 \mathrm{~s}$ in Fig. $12 \mathrm{~b}$ and $\mathrm{c}$ drops from an abundance of 65 to $25 \mathrm{ppb}(1 / e)$ in $0.3 \mathrm{~s}$. If this were limited by instrument response alone, that is if the plume were 
Atmos. Chem. Phys., 11, 10565-10578, doi:10.5194/acp-1110565-2011, 2011.

Duncan, B., Yoshida, Y., Olson, J., Sillman, S., Martin, R., Lamsal, L., Hu, Y., Pickering, K., Retscher, C., Allen, D., and Crawford, J.: Application of OMI observations to a space-based indicator of NOx and VOC controls on surface ozone formation, Atmos. Environ., 44, 2213-2223, doi:10.1016/j.atmosenv.2010.03.010, 2010

Edwards, P., Evans, M. J., Commane, R., Ingham, T., Stone, D., Mahajan, A. S., Oetjen, H., Dorsey, J. R., Hopkins, J. R., Lee, J. D., Moller, S. J., Leigh, R., Plane, J. M. C., Carpenter, L. J., and Heard, D. E.: Hydrogen oxide photochemistry in the northern Canadian spring time boundary layer, J. Geophys. Res.-Atmos., 116, D22306, doi:10.1029/2011jd016390, 2011.

Edwards, P. M., Young, C. J., Aikin, K., deGouw, J., Dubé, W. P., Geiger, F., Gilman, J., Helmig, D., Holloway, J. S., Kercher, J., Lerner, B., Martin, R., McLaren, R., Parrish, D. D., Peischl, J., Roberts, J. M., Ryerson, T. B., Thornton, J., Warneke, C., Williams, E. J., and Brown, S. S.: Ozone photochemistry in an oil and natural gas extraction region during winter: simulations of a snow-free season in the Uintah Basin, Utah, Atmos. Chem. Phys., 13, 8955-8971, doi:10.5194/acp-13-8955-2013, 2013.

Fortems-Cheiney, A., Chevallier, F., Pison, I., Bousquet, P., Saunois, M., Szopa, S., Cressot, C., Kurosu, T. P., Chance, K., and Fried, A.: The formaldehyde budget as seen by a global-scale multiconstraint and multi-species inversion system, Atmos. Chem. Phys., 12, 6699-6721, doi:10.5194/acp-12-6699-2012, 2012.

Fried, A., Olson, J. R., Walega, J. G., Crawford, J. H., Chen, G., Weibring, P., Richter, D., Roller, C., Tittel, F., Porter, M., Fuelberg, H., Halland, J., Bertram, T. H., Cohen, R. C., Pickering, K., Heikes, B. G., Snow, J. A., Shen, H., O'Sullivan, D. W., Brune, W. H., Ren, X., Blake, D. R., Blake, N., Sachse, G., Diskin, G. S., Podolske, J., Vay, S. A., Shetter, R. E., Hall, S. R., Anderson, B. E., Thornhill, L., Clarke, A. D., McNaughton, C. S., Singh, H. B., Avery, M. A., Huey, G., Kim, S., and Millet, D. B.: Role of convection in redistributing formaldehyde to the upper troposphere over North America and the North Atlantic during the summer 2004 INTEX campaign, J. Geophys. Res.-Atmos, 113, D17306, doi:10.1029/2007jd009760, 2008.

Gilpin, T., Apel, E., Fried, A., Wert, B., Calvert, J., Genfa, Z., Dasgupta, P. Harder, J. W., Heikes, B., Hopkins, B., Westberg, H., Kleindiens, T., Lee, Y.-N., Zhou, X., Lonneman, W., and Sewell, S.: Intercomparison of six ambient $\mathrm{CH}_{2} \mathrm{O}$ measurement techniques, J. Geophys. Res.-Atmos., 102, 21161-21188, 1997.

Hagopian, J.: Carbon nanotubes for stray light suppression, Art. 9417, NASA Tech. Briefs, 2011.

Hak, C., Pundt, I., Trick, S., Kern, C., Platt, U., Dommen, J., Ordóñez, C., Prévôt, A. S. H., Junkermann, W., Astorga-Lloréns, C., Larsen, B. R., Mellqvist, J., Strandberg, A., Yu, Y., Galle, B., Kleffmann, J., Lörzer, J. C., Braathen, G. O., and Volkamer, R.: Intercomparison of four different in-situ techniques for ambient formaldehyde measurements in urban air, Atmos. Chem. Phys., 5, 2881-2900, doi:10.5194/acp-5-2881-2005, 2005.

Hottle, J. R., Huisman, A. J., Digangi, J. P., Kammrath, A., Galloway, M. M., Coens, K. L., and Keutsch, F. N.: A Laser Induced Fluorescence-Based Instrument for In-Situ Measurements of Atmospheric Formaldehyde, Environ. Sci. Tech., 43, 790-795, 2009
Kaiser, J., Li, X., Tillmann, R., Acir, I., Holland, F., Rohrer, F., Wegener, R., and Keutsch, F. N.: Intercomparison of Hantzsch and fiber-laser-induced-fluorescence formaldehyde measurements, Atmos. Meas. Tech., 7, 1571-1580, doi:10.5194/amt-7-15712014, 2014.

Luecken, D. J., Hutzell, W. T., Strum, M. L., and Pouliot, G. A.: Regional sources of atmospheric formaldehyde and acetaldehyde, and implications for atmospheric modeling, Atmos. Environ., 47, 477-490, doi:10.1016/j.atmosenv.2011.10.005, 2012.

Marais, E. A., Jacob, D. J., Kurosu, T. P., Chance, K., Murphy, J. G., Reeves, C., Mills, G., Casadio, S., Millet, D. B., Barkley, M. P., Paulot, F., and Mao, J.: Isoprene emissions in Africa inferred from OMI observations of formaldehyde columns, Atmos. Chem. Phys., 12, 6219-6235, doi:10.5194/acp-12-62192012, 2012.

Meller, R. and Moortgat, G. K.: Temperature dependence of the absorption cross sections of formaldehyde between 223 and $323 \mathrm{~K}$ in the wavelength range $225-375 \mathrm{~nm}$, J. Geophys. Res.-Atmos., 105, 7089-7101, doi:10.1029/1999jd901074, 2000.

Millet, D. B., Jacob, D. J., Boersma, K. F., Fu, T. M., Kurosu, T. P., Chance, K., Heald, C. L., and Guenther, A.: Spatial distribution of isoprene emissions from North America derived from formaldehyde column measurements by the OMI satellite sensor, J. Geophys. Res.-Atmos., 113, D02307, doi:10.1029/2007jd008950, 2008.

Möhlmann, G. R.: Formaldehyde detection in air by laserinduced fluorescence, Appl. Spectrosc., 39, 98-101, doi:10.1366/0003702854249088, 1985.

Olaguer, E. P., Rappengluck, B., Lefer, B., Stutz, J., Dibb, J., Griffin, R., Brune, W. H., Shauck, M., Buhr, M., Jeffries, H., Vizuete, W., and Pinto, J. P.: Deciphering the Role of Radical Precursors during the Second Texas Air Quality Study, J. Air Waste Manage., 59, 1258-1277, doi:10.3155/1047-3289.59.11.1258, 2009.

Palmer, P. I., Jacob, D. J., Fiore, A. M., Martin, R. V., Chance, K., and Kurosu, T. P.: Mapping isoprene emissions over North America using formaldehyde column observations from space, J. Geophys. Res.-Atmos., 108, 4180, doi:10.1029/2002jd002153, 2003.

Palmer, P. I., Abbot, D. S., Fu, T. M., Jacob, D. J., Chance, K., Kurosu, T. P., Guenther, A., Wiedinmyer, C., Stanton, J. C., Pilling, M. J., Pressley, S. N., Lamb, B., and Sumner, A. L.: Quantifying the seasonal and interannual variability of North American isoprene emissions using satellite observations of the formaldehyde column, J. Geophys. Res.-Atmos., 111, D12315, doi:10.1029/2005jd006689, 2006.

Shibuya, K., Holtermann, D. L., Peacock, J. R., and Lee, E. K. C.: Fluorescence emission-spectroscopy, radiative lifetimes, and vibrational-relaxation rates of the 40 and 41 single vibronic levels of D2CO and HDCO (A1A2), J. Phys. Chem., 83, 940-944, doi:10.1021/j100471a012, 1979.

Weibring, P., Richter, D., Walega, J. G., and Fried, A.: First demonstration of a high performance difference frequency spectrometer on airborne platforms, Opt. Express, 15, 13476-13495, doi:10.1364/oe.15.013476, 2007.

Wert, B. P., Fried, A., Henry, B., and Cartier, S.: Evaluation of inlets used for the airborne measurement of formaldehyde, J. Geophys. Res.-Atmos., 107, ACH3.1-ACH3.13, doi:10.1029/2001jd001072, 2002. 
Wisthaler, A., Apel, E. C., Bossmeyer, J., Hansel, A., Junkermann, W., Koppmann, R., Meier, R., Müller, K., Solomon, S. J., Steinbrecher, R., Tillmann, R., and Brauers, T.: Technical Note: Intercomparison of formaldehyde measurements at the atmosphere simulation chamber SAPHIR, Atmos. Chem. Phys., 8, 21892200, doi:10.5194/acp-8-2189-2008, 2008.
Yokelson, R. J., Burling, I. R., Gilman, J. B., Warneke, C., Stockwell, C. E., de Gouw, J., Akagi, S. K., Urbanski, S. P., Veres, P., Roberts, J. M., Kuster, W. C., Reardon, J., Griffith, D. W. T., Johnson, T. J., Hosseini, S., Miller, J. W., Cocker III, D. R., Jung, H., and Weise, D. R.: Coupling field and laboratory measurements to estimate the emission factors of identified and unidentified trace gases for prescribed fires, Atmos. Chem. Phys., 13, 89-116, doi:10.5194/acp-13-89-2013, 2013. 